\title{
Should We Yak Back? Information Seeking among Yik Yak Users on a University Campus
}

\section{Elizabeth Price}

\begin{abstract}
Academic librarians have embraced tools such as e-mail or chat that allow them to deliver reference services virtually, but not many studies have advocated for using social networking sites (SNS) as a medium for answering user questions. Even as reference departments field fewer questions requiring in-depth resources or responses, librarians have not consistently examined how SNS might be employed for simple informational inquiries from university students who already view those sites as information-seeking tools. One such SNS is Yik Yak, a mobile app launched in 2013 that allows users to pose anonymous questions in a limited geographic range, such as a college or university campus. This study is an exploratory analysis of the postings on Yik Yak in the geographic area of a four-year, regional public institution during the 2015-2016 academic year. It argues that libraries should be more intentional about monitoring emerging information ecosystems such as Yik Yak to share their knowledge with users and to identify potential issues with library services.
\end{abstract}

\section{Introduction}

Increasingly, academic libraries have acknowledged the role of social networking sites (SNS) in the lives of their target audiences by creating Twitter or Facebook accounts to provide outreach and general information to their users. After all, 90 percent of young adults ages 18-29 used social networking sites in 2015. ${ }^{1}$ Rarely, though, are these tools studied within the library literature as a component of reference services. This is likely because the overall number of interactions occurring through SNS has been lower in studies that compared usage to more established methods for answering questions such as e-mail or instant messaging. ${ }^{2}$ Jill Benn and Dawn McLoughlin found many instances of SNS being used to promote reference services but few examples of integration. ${ }^{3}$ Young adults, however, increasingly turn to SNS for their everyday information needs, forcing businesses "to leverage [social] in everything they do, whether it's servicing their clients or talking to them or listening to what they care about." ${ }^{4}$ Academic librarians need to reconsider whether SNS should be integrated more deliberately into reference

Elizabeth Price is Business Librarian and Assistant Professor in the James Madison University Libraries and Educational Technologies; e-mail: price2el@jmu.edu. (C2018 Elizabeth Price, Attribution-NonCommercial (http://creativecommons.org/licenses/by-nc/4.0/) CC BY-NC. 
practice and which applications provide the best opportunities for extending services and interacting with students.

Unfortunately, it can be difficult to determine the return on investment (ROI) for the staff hours required to engage on a daily basis in virtual communities. Bettina Peacemaker, Sue Robinson, and Emily Hurst found that only 27 percent of libraries surveyed had a system of evaluation and measurement to determine effectiveness and time invested in social networking sites..$^{5}$ This diverged sharply from professionals in the public relations industry, where 52 percent were measuring use. ${ }^{6}$ Peacemaker et al. further noted an underlying theme among their respondents to wait-and-see before trying emerging platforms. ${ }^{7}$ Few librarians reported in 2014 that their organizations were using newer SNS such as Instagram $(26 \%)$ or Snapchat $(13 \%) .{ }^{8}$ One barrier is the staff time needed to check multiple sites per day and maintain a working proficiency with each of them. ${ }^{9}$ Other studies acknowledged that constant change within the social networking realm is a reason for cautious adoption. ${ }^{10}$ And yet these hesitations are not solely a response to the recent proliferation of SNS options; in her 2006 article about Brooklyn College Library's experiment with MySpace, Beth Evans noted: "Still, many librarians are stalled by indecision as to whether or not they should jump into the pool."11

This reluctance to use SNS, whatever its impetus, does not mean that students are not using these tools to ask questions. At Murray State University (MSU), one application used in this capacity is Yik Yak. This free mobile app created an ongoing online conversation with users in close geographical proximity. There were no restrictions on who could sign up, and users were not required to set up public profiles. After downloading the app to a mobile device, users could anonymously post questions or comments of up to 200 characters that could be seen by others within a 1.5- to 10-mile radius (though the app was disabled near middle and high schools to combat bullying). ${ }^{12}$ Founded by a pair of fraternity brothers in 2013, Yik Yak posts could include both text and images. The rules prohibited posts that contain any personally identifiable information such as names, phone numbers, street addresses, or social media accounts. ${ }^{13}$ The app allowed users to post in total anonymity or under self-selected handles. Those who chose not to post under handles were assigned icons in a variety of colors (orange paw, pink shovel, green acorn, blue sailboat, and the like) to allow for direct responses within the Yik Yak conversation thread. Popular posts were upvoted by the community, while unpopular sentiments could be deleted and disappeared permanently with five downvotes. ${ }^{14}$ Engagement with the platform (upvoting or downvoting or posting yaks that get upvoted) earned the user points (Yakarma). Yik Yak shut down in April 2017.

The geographic limitation made Yik Yak particularly popular among college and university students, with activity at more than 2,000 campuses as of January $2016 .{ }^{15}$ The anonymity it afforded allowed users to say anything on their mind without fear of judgment or retribution outside the app. The downside is that it created an accountability-free channel for violent, racist, and sexist speech. The app drew criticism in the mainstream media and higher education trade journals as a forum for racist commentary and threats on university campuses. ${ }^{16}$ Yet one study found that Yik Yak posts were only slightly more likely than Twitter posts to contain any of 355 identified vulgar words (6.29\% to $5.38 \%) .{ }^{17}$ Another study found little evidence of frequent pervasive racist, hate, or antisocial postings sufficient to merit "demonizing of the entire application." ${ }^{18}$ Both studies ultimately concluded that the Yik Yak community, through downvoting or flagging offensive posts, created an effective self-regulating mechanism to check bullying and antisocial behavior.

Overall, Yik Yak provided an intriguing tool to study the information-seeking behaviors of students on a particular campus. This article is an exploratory analysis using the postings on the social networking app Yik Yak in the geographic area of MSU, a four-year, regional public institution during a six-month period. 


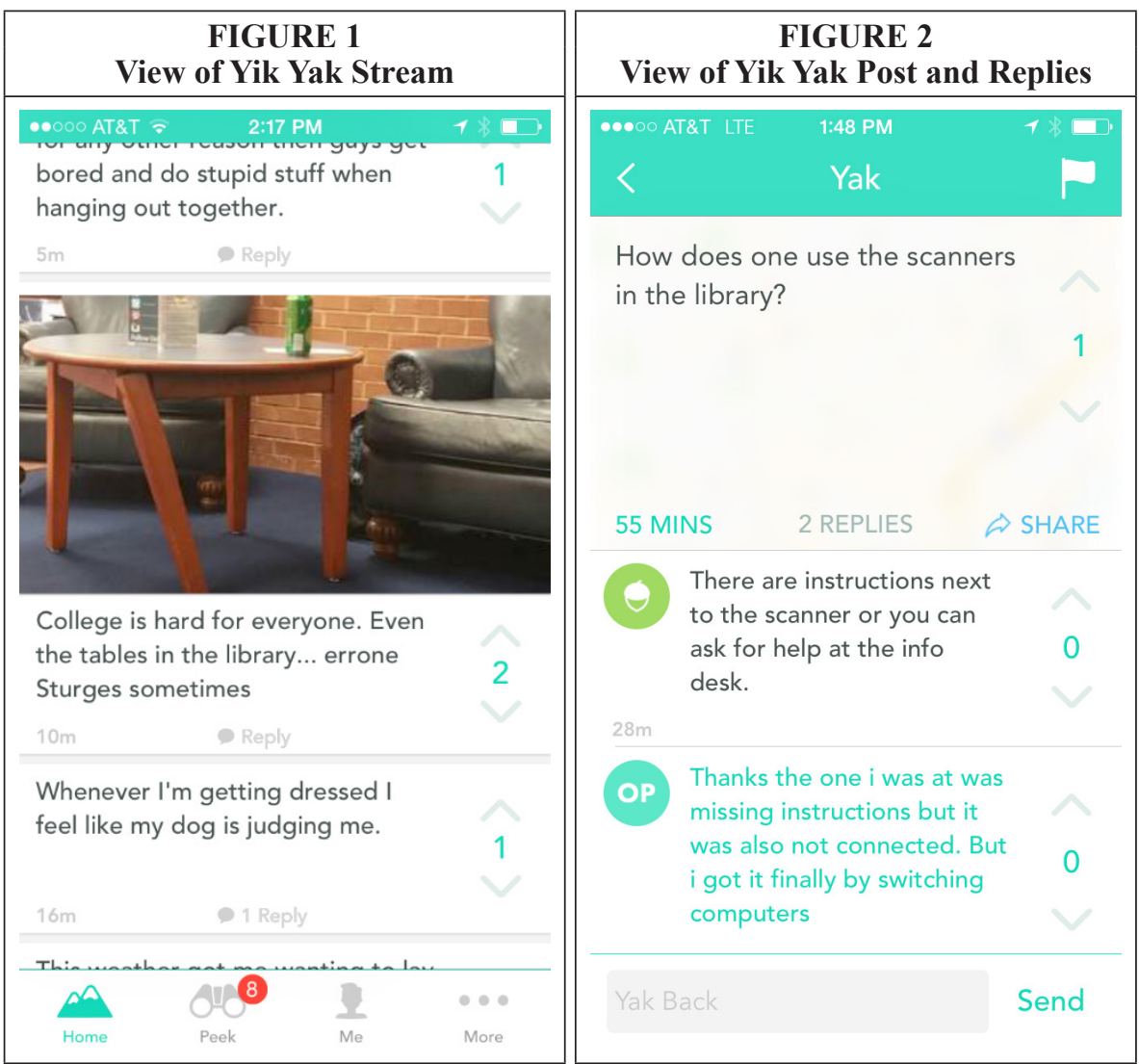

\section{Literature Review}

The Reference and User Services Association (RUSA) describes reference transactions as "information consultations in which library staff recommend, interpret, evaluate, and/or use information resources to help others to meet particular information needs." ${ }^{19}$ The organization specifies that "exchanges that provide assistance with locations, schedules, equipment, supplies, or policy statements" are not considered reference transactions. Perhaps that is why RUSA neglected SNS such as Facebook and Twitter in its definition of virtual reference services:

Reference service initiated electronically, often in real-time, where patrons employ computers or other internet technology to communicate with reference staff, without being physically present. Communication channels used frequently in virtual reference include chat, videoconferencing, Voice over IP, co-browsing, email, and instant messaging. ${ }^{20}$

This oversight might simply be because the committee's work preceded social networking sites' pervasiveness. The virtual reference (VR) guidelines were approved in 2004; Facebook launched that same year and Twitter in 2006. RUSA last revised the guidelines in 2009.

Many authors have written about using SNS in libraries (a SU search for "online social networks" OR "social media" AND SU "libraries" in the databases Education 


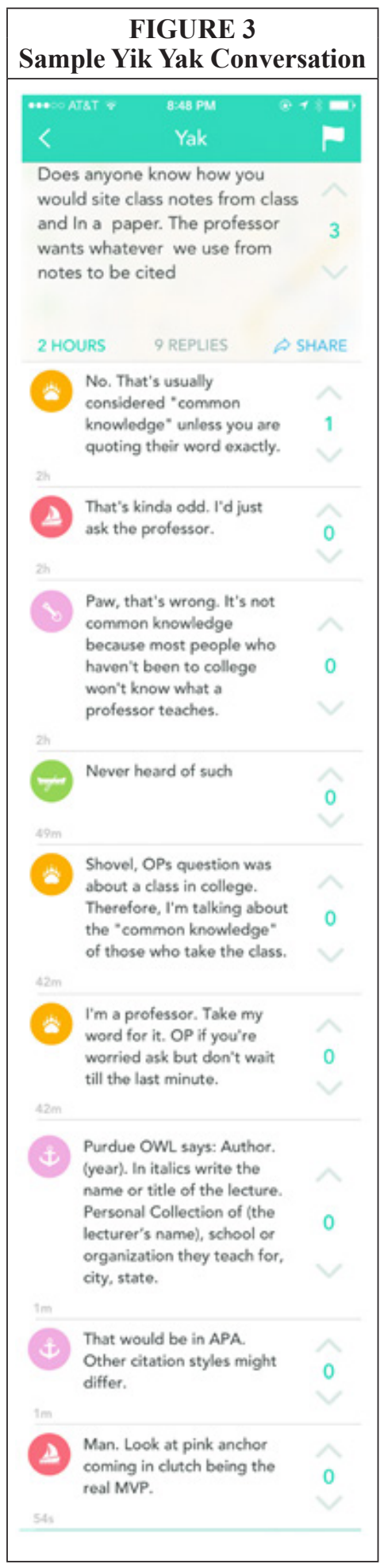

Resource Complete, Library, Information Science \& Technology Abstracts, Academic Search Complete, and OmniFile Full Text Mega yielded 2,378 results in November 2016), but most of the articles focus specifically on outreach opportunities, particularly in terms of promoting events and services. When the SU "reference services" was added and duplicates were removed, only 37 articles remained. Separate searches using SU "reference services" and specific platforms in the abstract $(\mathrm{AB})$ field garnered a few more articles (12 for Facebook, seven for Twitter, four for MySpace, one for Instagram) but the majority were duplicates. Those highlighted in this review address SNS as a means of answering user questions or as a component of reference services.

\section{SNS Use}

Khalid Mahmood and John V. Richardson reported that 90 percent of the Association of Research Libraries (ARL) surveyed said they were using social networking sites in 2010, and 88 percent of respondents agreed or strongly agreed that Web 2.0 tools were useful for effectively sharing library news, events, and announcements. ${ }^{21}$ In Leila June Rod-Welch's 2011 study of ARL member websites, 49 percent of libraries provided live chat or used Facebook and 46 percent used Twitter. ${ }^{22}$ About 70 percent of respondents to a survey of Asian, North American, and European librarians said their organizations were using SNS and saw the greatest benefit to be promoting library services. ${ }^{23} \mathrm{~A}$ Taylor and Francis white paper reported similar figures in 2014, with 68 percent of the 497 international libraries surveyed managing between one and four social media accounts. ${ }^{24}$

The popularity of the sites among teenagers and young adults also drive librarians' adoption of specific SNS. Andrea Forte, Michael Dickard, Rachel Magee, and Denise E. Agosto reported that 77 percent of high school students who responded to their survey had asked a question of their online social networks, ${ }^{25}$ while Kyung-Sun Kim, Sei-Ching Joanna Sin, and Eun Young Yoo-Lee found that nearly 96 percent of undergraduates used SNS as sources for acquiring information. ${ }^{26}$ Among teens aged 13 to 17, the Pew Research Center reported in 2015 that Facebook remained the most used site at 71 percent. ${ }^{27}$ Photo-sharing sites Instagram and Snapchat were used by 52 percent and 41 percent of teenagers, respectively; 
Twitter and Google+ tied for the next largest usage at 33 percent apiece. These sites all require users to create a profile and add or invite friends or followers. Yik Yak differs in that it was location based, creating a target audience within a particular community, and did not put the onus on the user to build a base or following. Yik Yak also allowed for completely anonymous interactions, a trend seen the last few years in other apps such as Whisper and Ask.FM. Pew reported that 11 percent of cell-phone owning teens aged 13-17 were using some type of anonymous-sharing app in 2015. ${ }^{28}$ One anonymous app targeted specifically at high school students, Afterschool, was on 22,300 campuses in December 2015..$^{29}$ Teenagers who are regularly interacting on anonymous platforms and seeking help from their peers will be the next generation of academic library users. Librarians will need to consider how information-seeking behaviors honed on anonymous SNS might influence how these students expect to interact with libraries when they have questions.

\section{Specific Cases of SNS Used to Answer Questions}

Benn and McLoughlin examined Facebook and Twitter use among the world's top 100 universities. While 44 percent of the librarians who responded used those SNS for client inquiries and feedback, they indicated less satisfaction with those technologies than with e-mail. ${ }^{30}$ A number of respondents indicated that low ratings stemmed from low student usage of those services. The authors reported only eight respondents (24\%) were integrating SNS with traditional forms of reference such as e-mail or chat. Undergraduates surveyed at Marywood University Library preferred e-mail research assistance to chat/IM or Facebook/MySpace, prompting Lizah Ismail to caution other librarians to solicit student feedback before implementing new technologies. ${ }^{31}$ Adeyinka Tella and Toyese Tunde Oyedokun found a low level of awareness of online reference services through SNS, leading to low use and less satisfaction among students. ${ }^{32}$ In selected Philippine academic libraries, nearly 80 percent of students surveyed were aware of digital reference services in their libraries, yet only 34 percent of them had used the services. ${ }^{33}$ Most preferred synchronous services such as IM or text reference when they wanted to learn more about the library rules, regulations, or schedules. Terra Jacobson found that only four of 12 library Facebook pages that she studied provided a way to ask a librarian for help. ${ }^{34}$ Only four of 115 (3\%) Western Michigan University students said they had asked a librarian a question via Facebook. Students, the authors concluded, appear to prefer "passively receiving information and are unlikely to use Facebook to actively request assistance. ${ }^{\prime 35}$ One librarian specifically encouraged undergraduate students to seek reference and research assistance via Facebook at Pennsylvania State University in fall semester 2006 and received more questions via the platform (126) than through e-mail (122) or in person (112). ${ }^{36}$ Scott Stone found a significant correlation between creating a friend connection with a library patron and the number of reference interactions in real life, even though only 3 percent of the 430 reference interactions during the study period occurred via the Facebook platform itself. ${ }^{37}$ Brooklyn College concluded that students had "genuine need[s] for information" on MySpace, even if users were initially surprised to find the library operating in that virtual space. ${ }^{38}$

Kaya van Beynen and Camielle Swenson monitored peer-to-peer library content and engagement in an existing, student-run Facebook group open to their entire campus. ${ }^{39}$ While the librarians used the Facebook group mostly to post about library events, students used it to ask for quick general library information from their peers, not the librarians. Raymond Pun piloted WeChat, a mobile app that allows users to send text, image, audio, and video messages for free, as a component of virtual reference services at New York University Shanghai. ${ }^{40}$ Dora Yu-Ting Chen, Samuel Kai-Wah 
$\mathrm{Chu}$, and Shu-Qin $\mathrm{Xu}$ assigned themes to posts on three SNS (Facebook, Twitter, and Weibo) for a sample of English-speaking and Greater Chinese university libraries. ${ }^{41}$ The themes were not assigned exclusively. More than half (53.4\%) of the interactions were information dissemination (news and announcements from the libraries), with another 28.3 percent deemed knowledge sharing (librarians or users share information resources). Less common themes included communication (librarian-user or user-user conversations) and knowledge gathering (harvesting information from individual users to improve library services, for example). These comprised 15.5 percent and 2.8 percent respectively of the 1,753 posts harvested.

Twitter is the SNS that has been most frequently adopted by librarians for some type of reference function. Gary Collins and Anabel Quan-Haase noted only Twitter was used for direct communication and interaction with patrons among the four SNS they studied. ${ }^{42}$ More than a fifth of tweets from four of the libraries they studied were in response to comments or questions from patrons. Evgenia Vassilakaki and Emmanouel Garoufallou, in a systematic review of libraries and librarians' Twitter use, analyzed 51 articles, of which only three papers addressed using Twitter to enhance reference services..$^{43}$ Darcy Del Bosque, Sam A. Leif, and Susie Skarl found less than 10 percent of the 101 libraries in their study were using Twitter accounts to answer reference questions; most tweeted to discuss resources (55\%), library events (24\%), and hours (14\%). ${ }^{44}$ Erin Fields discussed efforts to tweet questions answered during reference desk shifts with the hashtag \#refdesk. This communicates "that reference questions are not only being asked, but conversely, can be answered in the library." ${ }^{45}$ Katy Kelly and Hector Escobar recounted that directional and reference inquiries via Twitter increased when the University of Dayton's Roesch Library proactively retweeted and responded to tweets using the \#clubroesch hashtag that students had adopted. ${ }^{46}$ Valerie Forrestal noted the geographical opportunities that Twitter offers for proactive librarians. "You can be notified if someone uses the terms 'research,' 'paper' or 'writing' on Twitter within a mile of your location, giving you an opportunity to respond to the poster with research options at your library even if the user does not mention the word 'library.'" 47 This is a method for reaching students who might not realize how the library can help them. The downside of this type of proactive approach is that students can be "creeped out" about having the library respond to or retweet their messages, as noted by Steven Bell: "It clearly gave a distinct 'Big Brother' vibe, as in, they are watching us." 48

Besiki Stvilia and Leila Gibradze took it a step further with a content analysis of six library Twitter accounts to determine what makes a library tweet useful, measuring the numbers of retweets and favorites to determine utility. ${ }^{49}$ Of the nine types of tweets they identified, events were the most frequent (28.3\%). Q\&A, defined as "responses to reference questions and inquiries related to interlibrary loans, course reserves, conditions inside the library building (e.g. temperature), the availability of computer equipment, hours of operation and information technology support" (p. 6) made up only 6.6 percent of the 752 entries. The category that saw the most retweets and favorites was study support, which included tweets about various support services for students in the library and promoting the facility as a location to study.

\section{Methodology}

This study followed van Beynen and Swenson's exploratory analysis of content and engagement in a student-run Facebook group. ${ }^{50}$ Similar to that study, this one relies on qualitative and quantitative data to discover the information-seeking behaviors of anonymous SNS users in the geographic area around a rural university campus. The four questions that guided this inquiry were: (a) What purpose do SNS serve in 
reference services at academic libraries? (b) What kinds of questions are being asked and answered on SNS? (c) What can academic librarians learn about their facilities and services by monitoring SNS? (d) How should libraries plan to interact with users in peer-focused digital environments such as Yik Yak?

Two studies in particular lent themselves to developing the methodology used in this exploratory analysis: Chen, Chu, and Xu's types of SNS interactions between libraries and users and Stvilia and Gibradze's categorization of tweets and their usefulness. ${ }^{51}$

From November 1, 2015, through May 15, 2016, two Murray State University librarians monitored the Yik Yak feed around their campus. This required downloading the free Yik Yak app onto personal iPhones. Every day during the study period, librarians checked the app multiple times for posts (or yaks, as they are known to the app's users) that referenced library facilities or for posts that asked a question that might be answered by staff at the MSU Libraries' reference desk (identified locally as the Information Desk). Data collection consisted of screenshots of relevant yaks and replies that were saved to a shared iCloud account. These screenshots included the text or images that comprised the original post, as well as any subsequent user comments or upvotes at the time it was captured. These screenshots were taken seven days a week, four times per day (morning, afternoon, evening, and around midnight).

It should be emphasized that the Yik Yak feed was dynamic - new posts pushed off older ones continually and downvotes removed others. An active community might see only a few yaks that are older than 24 hours; a less active community might consist of posts that are days, weeks, or months old. None of the yaks were archived, making it impossible to know how many yaks were posted each day or even the total number posted during the span of this study. Therefore, it is not possible to say that every yak about the library or question asked was captured.

A library student assistant transferred the content of the original yaks and replies into an Excel spreadsheet that contained the following:

- Date captured

- Time captured

- Original yak

- Up/down votes received at time captured

- Subsequent replies at time captured

- Up/down votes for replies at time captured

Capitalization, punctuation, and emojis were documented as they appeared. In all, 282 yaks were captured and formed the data set for this study.

During summer 2016, three public services librarians independently classified the posts based on the content of the original yak to determine its type/purpose, modified from the types of SNS interactions identified by Chen, $\mathrm{Chu}$, and $\mathrm{Xu} .{ }^{52}$ Replies were

\begin{tabular}{|l|l|}
\hline \multicolumn{2}{|c|}{$\begin{array}{c}\text { TABLE 1 } \\
\text { Types of Yik Yak Posts }\end{array}$} \\
\hline $\begin{array}{l}\text { Information } \\
\text { Seeking }\end{array}$ & $\begin{array}{l}\text { Any question posed about the library, an assignment, the university, or the } \\
\text { community that the Information Desk staff would answer. }\end{array}$ \\
\hline Feedback & $\begin{array}{l}\text { Any compliment or complaint specific to library services, resources, or } \\
\text { facilities. }\end{array}$ \\
\hline $\begin{array}{l}\text { Student } \\
\text { Life }\end{array}$ & $\begin{array}{l}\text { Any mention of the library in day-to-day life or as a location for a student } \\
\text { activity that has little to do with library services. }\end{array}$ \\
\hline $\begin{array}{l}\text { Information } \\
\text { Providing }\end{array}$ & $\begin{array}{l}\text { Any post that seeks to answer an unasked question or announce an event or } \\
\text { service. }\end{array}$ \\
\hline
\end{tabular}




\begin{tabular}{|l|l|}
\hline \multicolumn{2}{|c|}{$\begin{array}{c}\text { TABLE 2 } \\
\text { Type of Information Sought }\end{array}$} \\
\hline Library Focused & Comments or questions about library staff, services, or facilities. \\
\hline Assignment Focused & $\begin{array}{l}\text { Comments or questions about writing citations, doing lit reviews, } \\
\text { changing file types, formatting papers, finding sources, or } \\
\text { otherwise related to specific courses. }\end{array}$ \\
\hline University Focused & $\begin{array}{l}\text { Comments or questions about university services or facilities or } \\
\text { about higher education procedures in general. }\end{array}$ \\
\hline Other & Comments or questions that do not fit into one of these categories. \\
\hline
\end{tabular}

treated as threads in the conversation and were not categorized independently. The librarians also could suggest that a post be removed from the data set if the connection to library and/or university services did not fit the four categories. The categories are shown in table 1.

From there, several secondary classifications were applied. For example, yaks in the information seeking category were analyzed to indicate whether the type of information sought was library focused, assignment focused, or university focused (see table 2).

Yaks in the feedback category were analyzed as positive, negative, or neutral. Last, yaks in both the information seeking and feedback categories underwent a third classification as to what aspects of library services they addressed. Four categories were developed based on Stvilia and Gibradze's types of tweets ${ }^{53}$ (see table 3).

After the coders completed the initial classification, the categories were discussed as a group and refined to make their boundaries clearer. Then a second classification was undertaken independently to arrive at the final data set. Eleven yaks were removed after this final classification because they were duplicates or they did not meet the scope of the study. An example of a yak that was cut because it had only a tangential relationship to library services is "Neon huffy I just took ur bike for a spin. Nice shocks. It's back in front of the library" or the connection was nonexistent ("Math class would be easier if it was treated like real life. Do professors not realize Google exists and that I'll more than likely never need to do equations for the rest of my life?"). That left 271 yaks in the data pool.

To examine how Yik Yak might fit into the reference repertoire, two additional measures were needed. All yaks classified as information seeking were analyzed to determine the following: a) where the question posed in the original post fell on the MSU Libraries' reference question classification scale; and b) whether the replies that the original poster received were accurate.

\begin{tabular}{|l|l|}
\hline \multicolumn{2}{|c|}{$\begin{array}{c}\text { TABLE 3 } \\
\text { Subject of Library-focused Yaks }\end{array}$} \\
\hline Building & $\begin{array}{l}\text { Content about the library facilities, such as smells, temperatures, furniture, } \\
\text { noise, space, outlets, bathroom, or the environment as a whole. }\end{array}$ \\
\hline Resources & $\begin{array}{l}\text { Content about traditional library research sources, such as books, } \\
\text { subscription databases, and software and computer resources provided by } \\
\text { the library, including Wi-Fi, copiers, and printers. }\end{array}$ \\
\hline Operations & $\begin{array}{l}\text { Content about the library such as hours of operation, power or network } \\
\text { outages, air-conditioning or heating problems, staffing, or policies. }\end{array}$ \\
\hline $\begin{array}{l}\text { Study } \\
\text { Support }\end{array}$ & $\begin{array}{l}\text { Content about the library as a study location and the various support services } \\
\text { for students housed within the facility (writing center, oral communication } \\
\text { center, instruction, information desk, and other services). }\end{array}$ \\
\hline
\end{tabular}




\begin{tabular}{|c|c|c|}
\hline \multicolumn{3}{|c|}{$\begin{array}{c}\text { TABLE } 4 \\
\text { Murray State University Libraries' Reference Question Classification Scale }\end{array}$} \\
\hline Level & Term & Description \\
\hline 1 & Directional & $\begin{array}{l}\text { Assistance finding locations within the library or } \\
\text { elsewhere on campus. Staff seldom consult resources } \\
\text { to answer these questions. }\end{array}$ \\
\hline 2 & Technology Help & $\begin{array}{l}\text { Assistance using printers, copiers/scanners, Wi-Fi, or } \\
\text { software. }\end{array}$ \\
\hline 3 & $\begin{array}{l}\text { Simple Instruction/ } \\
\text { Reference }\end{array}$ & $\begin{array}{l}\text { Assistance to locate one specific item or resolving a } \\
\text { basic question that might require consulting a single } \\
\text { resource (example question: Do you have this book?). }\end{array}$ \\
\hline 4 & $\begin{array}{l}\text { Moderate Instruction/ } \\
\text { Reference }\end{array}$ & Assistance looking up a couple of books or articles. \\
\hline 5 & $\begin{array}{l}\text { Advanced Instruction/ } \\
\text { Reference }\end{array}$ & $\begin{array}{l}\text { Assistance using a database or looking up a number of } \\
\text { items. }\end{array}$ \\
\hline
\end{tabular}

To determine how the questions posed on Yik Yak are similar to those answered at the Information Desk, all information seeking yaks were categorized using the five-level scale that the MSU Libraries has used since 2013-2014 for assessment of reference transactions. No official documentation explains the differences between these types of questions, but they are informally described in table 4 .

A normalization process is recommended - regardless of the scale being used - for more accurate assessment of reference transactions; however, the MSU Libraries do not formally undertake one. ${ }^{54}$ Therefore, the librarians aim for consistency in entering personal responses, even if coding is not necessarily standardized across desk workers. As a result, the coding of the original information seeking posts on Yik Yak was undertaken by a single librarian.

Finally, each reply posted to an information seeking yak was evaluated as to its accuracy (coded as either true or false). This required a literal interpretation of the response without trying to infer the poster's intent. For example, this thread took place in fall semester 2015:

Original poster: Where's the bathroom in the library?

Black mushroom: There aren't any.

Red flashlight: 3rd floor

MSU's main library, Waterfield, was in the middle of a renovation at the time of the original yak, so perhaps the only bathrooms known to the user "black mushroom" were closed and he/she did not realize that others were operational. Or perhaps "black mushroom" was simply being obnoxious. For this study, however, "There aren't any" was taken as a literal belief that Waterfield Library had no working bathrooms and thus was coded as inaccurate (false). Other questions dealt with time-sensitive information ("Are there any computers open right now?") that could not be confirmed at the time of the data analysis and were not factored into the accuracy rating.

\section{Findings}

The MSU Libraries captures data about the research-related and directional questions it answers at the Information Desk throughout the academic year using LibAnalytics. During the period of data collection for this project (November 1 through May 15), librarians and graduate students answered 2,767 questions at the Information Desk. 


\begin{tabular}{|l|c|c|c|}
\hline \multicolumn{4}{|c|}{ TABLE 5 } \\
\hline \multicolumn{4}{|c|}{ Questions Answered at MSU Information Desk } \\
\hline In-person of Inquiry & $\mathbf{2 0 1 4}$ & $\mathbf{2 0 1 5}$ & $\mathbf{2 0 1 6 *}$ \\
\hline Chat & 3,932 & 2,544 & 1,775 \\
\hline E-mail & 66 & 60 & 55 \\
\hline Text & 102 & 76 & 51 \\
\hline Phone & 129 & 53 & 63 \\
\hline Social Media & 376 & 324 & 822 \\
\hline Total & 0 & 0 & 1 \\
\hline$*$ Questions asked only from November 1 through May 15 during each academic year. \\
\hline
\end{tabular}

\begin{tabular}{|c|c|c|}
\hline \multicolumn{3}{|l|}{$\begin{array}{c}\text { TABLE } 6 \\
\text { Examples of Different Types of Yaks }(n=271)\end{array}$} \\
\hline & Count & $\%$ \\
\hline $\begin{array}{l}\text { Information Seeking } \\
\text { Examples: } \\
\text { 1. Where's somewhere I can do homework late at night when the } \\
\text { library is closed? } \\
\text { 2. Is that thing with Waterfield Library painted on the side outside } \\
\text { the college gate a book return? } \\
\text { 3. Is there any way to set these library laptops to where you can } \\
\text { unmute them? }\end{array}$ & 105 & $39 \%$ \\
\hline $\begin{array}{l}\text { Student Life } \\
\text { Examples: } \\
\text { 1. I've decided I'm spending the weekend in the library in hopes } \\
\text { that a cute boy will approach me even though we all know that } \\
\text { won't happen. Maybe I'll actually get work done. } \\
\text { 2. In the library with good music, good headphones, a good book, } \\
\text { and good coffee-it's gonna be a great day. } \\
\text { 3. Oh no... just saw a couple hooking up in the library... my bad }\end{array}$ & 80 & $30 \%$ \\
\hline $\begin{array}{l}\text { Feedback } \\
\text { Examples: } \\
\text { 1. Our library seriously needs upgrading... Like put some [d---] } \\
\text { outlets in all the tables or something! } \\
\text { 2. it's too hot to even [f------] study in the library anymore and it's } \\
\text { genuinely affecting my grades } \\
\text { 3. The bathrooms on the second floor of the (main) library are so } \\
\text { gross. Why would they have only one set for all three floors? }\end{array}$ & 73 & $27 \%$ \\
\hline $\begin{array}{l}\text { Information Providing } \\
\text { Examples: } \\
\text { 1. April 18th ... that's the audit/drop deadline. I know it's gonna } \\
\text { be asked soon. } \\
\text { 2. PSA: The library is open today. I don't know why some people } \\
\text { think it's closed today. But it is open. I'm here right now study- } \\
\text { ing and doing homework. } \\
\text { 3. Waterfield Library update. Crazy crowded upstairs and hot. } \\
\text { Basement is slightly less packed and not as hot. }\end{array}$ & 13 & $5 \%$ \\
\hline
\end{tabular}




\begin{tabular}{|c|c|c|}
\hline \multicolumn{3}{|l|}{$\begin{array}{c}\text { TABLE } 7 \\
\text { Type of Information Sought }(\mathbf{n}=\mathbf{1 0 5})\end{array}$} \\
\hline & Count & $\%$ \\
\hline $\begin{array}{l}\text { Library Focused } \\
\text { Examples: } \\
\text { 1. Where's the bathroom in the library? } \\
\text { 2. Where's the media room in Waterfield? } \\
\text { 3. Are the library printers color? }\end{array}$ & 51 & $49 \%$ \\
\hline $\begin{array}{l}\text { Assignment Focused } \\
\text { Examples: } \\
\text { 1. Is there anyone who has had ARG } 322 \text { and can help me with } \\
\text { my lab report? I don't understand the whole APA format } \\
\text { thing. } \\
\text { 2. Lit. Review due tomorrow that I still don't understand how } \\
\text { to do... } \\
\text { 3. Where can I go to get help on writing my paper? }\end{array}$ & 5 & $5 \%$ \\
\hline $\begin{array}{l}\text { University Focused } \\
\text { Examples: } \\
\text { 1. Anyone know where the dean's office is? } \\
\text { 2. Where do I look up the books I need this semester on MyGate? } \\
\text { 3. Does TR stand for Tuesday and Thursday or just Thursday? }\end{array}$ & 42 & $40 \%$ \\
\hline
\end{tabular}

\begin{tabular}{|l|c|c|}
\hline \multicolumn{2}{|c|}{ Tone of Feedback (n= 67) } & Count \\
\hline
\end{tabular}




\begin{tabular}{|c|c|c|}
\hline \multicolumn{3}{|l|}{$\begin{array}{c}\text { TABLE } 9 \\
\text { Subject of Library-focused Yaks }(n=119)\end{array}$} \\
\hline & Count & $\%$ \\
\hline $\begin{array}{l}\text { Building } \\
\text { Examples: } \\
\text { 1. Are the first floor bathrooms in Waterfield open again? } \\
\text { 2. I love how all the phone charging stations in the library don't } \\
\text { work } \\
\text { 3. The library basement smells like someone needs to take a shower } \\
\text { really badly. }\end{array}$ & 69 & $58 \%$ \\
\hline $\begin{array}{l}\text { Operations } \\
\text { Examples: } \\
\text { 1. What happens if my library books are overdue? } \\
\text { 2. Is the library open today? } \\
\text { 3. Wouldn't it make more sense for waterfield to be open } 24 \text { hours } \\
\text { this weekend instead of next week? So we can study BEFORE } \\
\text { our finals not during them? }\end{array}$ & 22 & $18 \%$ \\
\hline $\begin{array}{l}\text { Resources } \\
\text { Examples: } \\
\text { 1. The desktops at Waterfield are like needy boyfriends: if you } \\
\text { don't touch them for a minute, they get mad at you and remind } \\
\text { you. } \\
\text { 2. People who take up library computers to watch Netflix or play } \\
\text { games need to be forcibly removed from society. } \\
\text { 3. Anybody know how much it costs to get copies done in the } \\
\text { library? }\end{array}$ & 19 & $16 \%$ \\
\hline $\begin{array}{l}\text { Study Support } \\
\text { Examples: } \\
\text { 1. Is the writing center really helpful in Waterfield? Like does [it] } \\
\text { help you on your paper? } \\
\text { 2. Is there popcorn in the library? } \\
\text { 3. Are the people in the oral communications center friendly? }\end{array}$ & 9 & $8 \%$ \\
\hline
\end{tabular}

The number of inquiries has declined over the last three years. During identical periods (November 1 through May 15) in the 2013-2014 and 2014-2015 academic years, those numbers were 4,605 and 3,057 respectively. Table 5 shows a breakdown of questions by method asked.

The questions that the librarians answered on Yik Yak in 2015-2016 were not counted in these totals. As a whole, only one social media reference was answered and logged at the Information Desk during the period studied. This shows that, while the MSU Libraries recognize the potential for patrons to ask questions via SNS, this route is not integrated into reference practice. Yet this exploratory analysis revealed that the library-related posts captured on Yik Yak were predominantly information seeking (39\%). Mentions of any of the three MSU library facilities (Waterfield Library, Pogue Library, or Overby Law Library) as a central component of daily student life were the second most common reference (30\%), while feedback specific to the libraries was close behind (27\%). Yik Yak was rarely used as a means of providing information (5\%). Interrater reliability among the three coders was 83 percent. Table 6 provides examples of each of these types of yaks. 


\begin{tabular}{|l|c|c|c|c|}
\hline \multicolumn{5}{|c|}{ TABLE 10 } \\
\hline & $\begin{array}{c}\text { Information } \\
\text { Desk } \\
\text { Questions } \\
\text { in 2013-14 }\end{array}$ & $\begin{array}{c}\text { Information } \\
\text { Desk } \\
\text { Questions } \\
\text { in 2014-15 }\end{array}$ & $\begin{array}{c}\text { Information } \\
\text { Desk } \\
\text { Questions } \\
\text { in 2015-16 }\end{array}$ & $\begin{array}{c}\text { Yik Yak } \\
\text { Information } \\
\text { Seeking } \\
\text { Questions }\end{array}$ \\
& $\mathbf{( n = 4 , 6 0 2 )}$ & $\mathbf{( n = 3 , 0 4 6 )}$ & $(\mathbf{n = 2 , 7 6 0 )}$ & $\mathbf{( n = 9 7 )}$ \\
\hline Directional & $2,171(47 \%)$ & $1,325(43 \%)$ & $1,450(52 \%)$ & $38(39 \%)$ \\
\hline Technology Help & $1,084(24 \%)$ & $750(25 \%)$ & $551(20 \%)$ & $18(19 \%)$ \\
\hline Simple Instruction/Reference & $1,183(26 \%)$ & $870(28 \%)$ & $676(24 \%)$ & $41(42 \%)$ \\
\hline $\begin{array}{l}\text { Moderate Instruction/ } \\
\text { Reference }\end{array}$ & $130(3 \%)$ & $87(3 \%)$ & $67(2 \%)$ & $0(0 \%)$ \\
\hline $\begin{array}{l}\text { Advanced Instruction/ } \\
\text { Reference }\end{array}$ & $34(1 \%)$ & $14(0 \%)$ & $16(1 \%)$ & $0(0 \%)$ \\
\hline
\end{tabular}

Each of the 105 original yaks classified as information seeking was then analyzed to see whether the question posed was about library services, an assignment, or university services. As most of the samples were collected because they were about library services, that is the largest category (49\%). Questions about university services were not far behind (40\%) and were the types of questions commonly posed at the libraries' Information Desk. Very few questions (5\%) were assignment focused that might be related to library skills indirectly (citations, file saving, steps in the research process, and so on). The remaining seven questions did not fit into one of these categories and were described as "other." Interrater reliability averaged 80 percent for this classification.

The yaks that were identified as feedback about library facilities or services were coded as either positive $(6 \%)$, negative $(85 \%)$, or neutral $(9 \%)$. This category proved among the most difficult to classify, with the lowest average interrater reliability $(62 \%)$ in the analysis.

Among the library-focused yaks (pulled from yaks identified as in either information seeking/library focused or feedback categories), 119 were identified and coded. Most of these were building related (58\%). Questions about library operations were next most common (18\%), followed closely by resources (16\%). Posts about study support services were least frequent $(8 \%)$. Interrater reliability was 76 percent for this category.

Among the questions posed via the information seeking yaks, 42 percent would be classified as requiring Simple Instruction/Reference if it had been asked at the Information Desk (see table 9). These types of questions might require the desk worker to consult a single source (such as the public access catalog, reserve list, library website, or university website) to provide an accurate answer about locating a known item or finding documentation of a particular policy. Virtual versions of the directional inquiries that Information Desk workers often receive (such as the locations of bathrooms, printers, or copy machines) were next most common at 39 percent. Technology help queries were 18 percent of the Yik Yak pool (such as using a scanner or connecting to Wi-Fi). No questions were posed among the information seeking yaks that the Information Desk would classify as requiring Moderate or Advanced Instruction/Reference assistance. In contrast, these types of inquiries compose approximately 3 percent of Information Desk transactions over the same periods in the 2013-2014, 2014-2015, and 2015-2016 academic years. 
Overall, Yik Yak users who asked information seeking questions on the MSU feed received an accurate reply 79 percent of the time (77 of 98 replies could be verified at time of analysis). Accuracy rates for inquiries answered by the MSU Information Desk were not analyzed as part of this study.

\section{Discussion}

The MSU Libraries saw a 40 percent drop in the number of questions being answered by the Information Desk from 2014 to 2016. This more than doubles the 14 percent decline in reference transactions among the nation's top 60 college and university libraries from 2010 to 2012. ${ }^{55}$ The MSU research and instruction librarians attributed these decreases to three main factors: a) more targeted information literacy instruction through the creation of disciplinary scaffolds; b) the creation of a knowledge bank for frequently asked questions through the LibAnswers platform; c) a shift in staffing at the Information Desk away from librarians and toward graduate assistants who might not be as diligent in recording interactions. Another contributing factor, as demonstrated by this exploratory analysis, might be a shift in Directional and Simple Instruction/ Reference questions aimed toward peers on SNS that exist outside traditional reference workflows. Data collection during the 2015-2016 academic year showed that Yik Yak was used for that purpose at MSU. This is likely based in part on convenience. Lynn Silipigni Connaway, Timothy J. Dickey, and Marie L. Radford found that "convenience is a situational criterion in people's choices and actions during the information-seeking process." ${ }^{56}$ If going to the library website or the Information Desk is viewed as another step in the process, this might explain why Yik Yak saw an increase in the number of questions that might previously have been asked through the MSU Libraries' formal VR channels. Students already were checking SNS on their phones, so it was simply easier to post the question there. In addition, students might believe that they are more likely to get a quicker and more direct response from one of their peers. Librarians' eagerness to instruct users how to find the information rather than providing an answer could be viewed as tiresome or inefficient. ${ }^{57}$ Third, Yik Yak offers the ability to ask (or answer) questions anonymously. This ability to control self-presentation makes it tremendously attractive to young people who guard their identities, as Forte et al. noted: "If people see you asking, they may realize that you don't know about something, and/or, perhaps equally revealing, that you want to." ${ }^{\prime 58}$ Take these two examples from the Yik Yak feed:

\section{Example 1:}

Original poster: Im a stupid freshman. Will someone explain to me what dead week is all about?

\section{Example 2:}

Original poster (OP): yo how you make copies in the library??

Yellow shovel: On the copy machine

OP: where's that? im a noob ${ }^{59}$

Pink map: Lol

Blue socks: 3 on main floor. Know where the men's restroom is? One right around the corner. Need $\$ 1$ s or change.

OP: thanks a million

Students are willing to admit anonymously what they do not know, when they might be too afraid to ask a peer about a topic they think everyone else already understands. 
This is true within the teacher-student role as well. Jill L. Creighton, Jason W. Foster, Libby Klingsmith, and Darren K. Withey cited one student who commented: “It's easier to be like I need help with this [on a social media platform] instead of looking at them and being embarrassed." The authors concluded: "Limiting face-to-face discussion means limiting personal embarrassment or shame." ${ }^{60}$ Past studies have shown that this dynamic extends to librarian-student interactions as well. ${ }^{61}$

Van Beynen and Swenson theorized students asked questions on the campus Facebook group rather than contacting a librarian for a different reason: because it "removed any connotations of discomfort from formality and/or authority intrusion." ${ }^{62}$ The concept of intrusiveness is not one to be taken lightly when evaluating how and/ or whether librarians should engage with SNS users. Jan H. Kietzmann, Kristopher Hermkens, Ian P. McCarthy, and Bruno S. Silvestre warned of the dangers of organizations inserting themselves into or manipulating a conversation on SNS: "[Companies that] know when to chime in - and, when not to-show their audience that they care, and are seen as a positive addition to the conversation; this is in contrast to [companies that] flood conversations that were not 'theirs' in the first place." ${ }^{\prime 63}$ As the following examples demonstrate, Yik Yak's users view the audience for their posts as students and might be antagonistic toward those who identify online as different.

\section{Example 3:}

Original poster: "Hello kind peers could anyone tell me how busy the library is so I know whether or not to drive across after work? Thanks in advance"

\section{Example 4:}

Original poster: Is it true I can get Microsoft Office for free if I'm in CSC or is my professor lying?

\section{Example 5:}

Original poster: Professors do use Yik Yak

Blue shovel: What class and can upvotes help my grade?

Blue teepee: Cool. Thanks. I was dying to know. Now I can die in peace.

Red sailboat: Shouldn't you have a wife and kids and not be using an anonymous app for thirsty ${ }^{64}$ college kids?

Similar sentiments were expressed on multiple occasions during the six months that librarians were monitoring the Yik Yak feed around MSU. This perceived student ownership of the virtual community makes Yik Yak an information ecosystem more similar to social Q\&A (SQA) sites such as Yahoo Answers or Quora. On these sites, "users ask, answer, and rate content while interacting around it." 65 One byproduct of this interaction is the endorsement of incorrect responses, which can be frustrating for users trying to provide accurate information. In example 6, an erroneous answer (12 a.m.) was upvoted instead of the correct one that the librarian posted.

\section{Example 6:}

Original poster: How late is Waterfield open?

Yellow boot: 12 (1 upvote)

Orange mushroom: 1 (0 upvotes) 


\section{Brown acorn: 2 (-2 downvotes)}

Orange mushroom: It doesn't close if you are good at hide and seek. (5 upvotes)

Yellow shovel (aka the librarian): 12:30 am (-1 downvotes)

Yellow binoculars: lol did you ever stayed the night there mushroom? ( 0 upvotes)

Despite this example, replies on the original Yik Yak posts analyzed in this study were accurate 79 percent of the time; recent studies examining accuracy in reference transactions have been between 79 and 93 percent. ${ }^{66}$ Accuracy, however, might not always be paramount to users asking questions on SNS. In a study comparing users' perceptions of SQA and library virtual reference (VR), Yin Zhang and Shengli Deng found enjoyment, promptness, and accessibility to be higher when using SQA even though users rated VR as more trustworthy and higher quality. ${ }^{67} \mathrm{~A}$ lack of awareness of VR might explain this sacrifice; studies have reported that college students might not know libraries provide VR and could be an option in their information seeking. ${ }^{68}$

Benn and McLoughlin detected little evidence that social networking would take over the role of traditional VR services. They cited both the open and identifiable forum of SNS and their suitability to answer shorter, more specific inquiries as barriers to their growth capacity. ${ }^{69}$ This exploratory study did not provide evidence to the contrary. The nature of the questions asked on Yik Yak rarely met RUSA's definition of a reference transaction; 100 percent fell into the lower end of the MSU Libraries' classification scale as Directional, Technology Help, or Simple Instruction/Reference. ${ }^{70}$ Librarians have argued that answering those types of questions does not make the best use of their skills or time, but it should be noted that 97 percent of the questions answered at the MSU Information Desk over the period of this study fell into those same three categories (see table 10).

Setting aside the weightier quandary of reference desk staffing, the fact remains that library users do have common if uncomplicated questions and they do not always voice them via traditional reference avenues. One way to address this gap might be to develop marketing strategies to combat students' lack of awareness of library VR. Another option is to more actively monitor emerging SNS for those questions libraries might be missing. To discount informational inquiries on emerging SNS - whether because of the proliferation of platforms, uncertainty about their longevity, or ignorance about their relevance-is simply not good customer service. Social technologies enable us to move beyond the reference desk to help our users; why not embrace Brian Mathews' tenet that "Instead of forcing them to come to us, we can restructure ourselves around them?"71 To limit the potential for instruction about library services to established SNS or VR is short-sighted. To succeed, though, reference staffs might need to embrace "perpetual beta" when it comes to instruction or assistance using SNS: recognizing that services need to be dynamic and responsive to user behavior with processes for gathering and incorporating frequent feedback into service provision. ${ }^{72}$ This will require more nimbleness on the part of reference staff to be attuned to trending SNS and to experiment with and then discard them as they peak and ebb. As one respondent in the Peacemaker et al. survey noted: "Platforms are constantly changing and people are not locked into just one platform...I think it is important to be open to other platforms taking over and to be aware where our audience is." ${ }^{173}$ Sensitivity to each campus's unique information culture will be vital: not every library needs to answer questions on Yik Yak, just as not every campus has a peer-to-peer Facebook group or student-selected library hashtag on Twitter. Libraries should more aggressively seek out opportunities to interact within existing or emerging ecosystems on campus, even if involvement would be beneficial in the short term but the commitment is not long term. As Peacemaker et al. recommended, this means creating evaluation and measurement systems 
that allow librarians to justify eliminating platforms, services, or outreach tools that are not working and actually following through with cessation. ${ }^{74}$

This study demonstrated that anonymous apps could be another service point worth monitoring on campus. Rather than tapping librarians for this role, a better solution might be to enlist library student assistants already using SNS to act as surrogates in these environments. Coastal Carolina University, California Polytechnic State University San Luis Obispo, and Grand Valley State University wrote about successful implementation of peer reference models; librarians at Texas A\&M University planned to stretch this concept further by implementing a "street team" of undergraduate volunteers to promote library workshops and new resources through the "students' own grapevine and information networks." 75

Actively monitoring SNS provides a secondary benefit to libraries because they reveal what users think of facilities and services. As Kietzmann et al. described it, these "conversations are like pieces of a rapidly changing puzzle which, when aggregated, combine to produce an overall image or message." ${ }^{\prime 6}$ Of the yaks posted that were categorized as feedback about library services, 85 percent were perceived by the librarians to be negative. Though interrater reliability was low for this portion of the study because of the difficulty in discerning the user's intent, it is clear that users are far more likely to complain online than to compliment. Lyndelle Gunton and Kate Davis posited: "As users increasingly live their lives connected to [SNS], it is important for libraries to tune in to hear what their customers might be saying about them. Even more importantly, libraries must actively address the concerns their customers raise in public channels." ${ }^{77}$ This author argues that Yik Yak is not necessarily the place to address those complaints directly, as it might lead to hostile exchanges by users who do not view the app as an appropriate venue for "official" communication. Libraries, however, should be analyzing feedback shared in this forum and brainstorming strategies for improvement. Overall, the ability to exploit Yik Yak and similar apps as "service recovery" mechanisms is an opportunity that libraries cannot continue to ignore if they wish to remain relevant to users. ${ }^{78}$

\section{Limitations and Future Directions}

Unlike Twitter or Facebook, Yik Yak posts were ephemeral. Five downvotes removed any yak from the local stream with no archive or record of its ever having existed. Information-seeking yaks were frequent targets for removal during the period of this study. At one point, the author was answering a question about color printing in the libraries and the yak disappeared in the middle of typing the response. This might have reflected users' attempts to enforce their perceived purpose on the local Yik Yak community: not as an information-seeking tool but as a place to share insights, voice complaints, and make connections. One user who posted an information-seeking yak received several replies that he/she described as helpful and commented, "OK I appreciate all of you who offer words of advice rather than downvote this question."

The anonymity of the app and data collection practices of Yik Yak, Inc., made it impossible to know how many users there were, what their demographics were, whether they were actually university students, or how many posts occurred in a given area or during a particular timeframe. Additionally, the lack of an archive made data capture cumbersome. The app's terms of use meant that phone numbers, full names, or addresses were not permitted, limiting librarians' ability to refer users to other helpful resources. It also cannot be discounted that viewing the feed had the potential to make some staff members uncomfortable. Besides incidents of hate speech and bullying, Yik Yak saw explicit posts about a variety of sexual matters. Profanity was equally unavoidable. Library administrators rightfully might have been hesitant to mandate that faculty, staff, or student surrogates engage in this environment. 


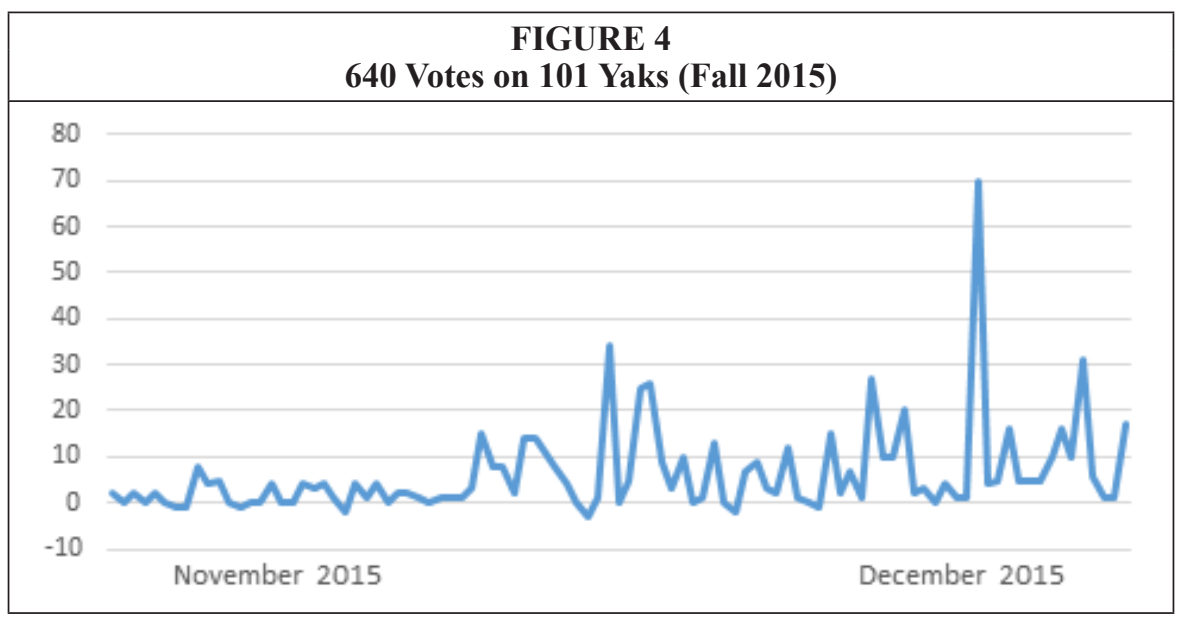

Most notably, social networking apps are constantly changing and popularity can be fleeting. Yik Yak ultimately proved fleeting; the app shut down in April 2017. Forte et al. put it best: "It is worth noting the difficulty of capturing something as slippery as social media practices. Sites can become terrifically popular in a short period of time and, similarly, fall out of favor among specific groups." ${ }^{\prime 79}$ In this study, librarians saw fewer votes on posts during data collection toward the end of the spring semester, signifying that Yik Yak's popularity on the MSU campus already was waning.

\section{Conclusion}

Despite its negative reputation, anonymous SNS are an interesting tool for seeing what users are asking about library or university services. The unfiltered insights become a resource that librarians should be monitoring for a few reasons. First, we need to recognize that students are seeking information on SNS. Even though there has been limited success using SNS directly for reference services in the past, new efforts must be made to figure out how to use them more appropriately to resolve users' information needs. Second, academic librarians should continue to monitor new SNS to see how students incorporate them into their academic and professional lives. Teenagers

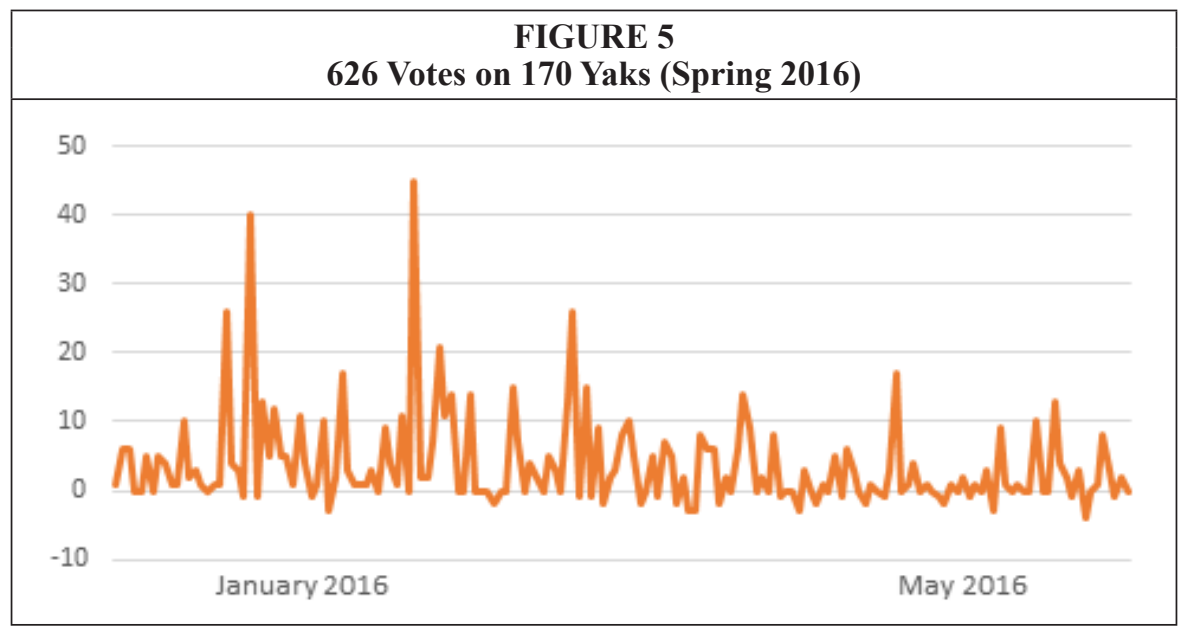


and young adults are heavier users of emerging platforms, meaning that academic librarians cannot afford to restrict our focus to the safer legacy sites. Snapchat, for example, has been around since 2011, and 45 percent of its active users are ages 13-24; Instagram debuted in 2010, and 53 percent of its users are between 18 and $29 .{ }^{80}$ SNS need to be more systematically integrated into library workflows for inquiries that require quick, brief responses. To make these experiments successful, agile staff will need to accommodate bursts of activity on these new platforms and then regularly assess whether each is still a worthwhile outreach mechanism. Assessment requires policies for measuring successful engagement. If the ROI is too low, librarians should be prepared to end outreach on sites with declining relevance. ${ }^{81}$ Uncertainty cannot continue to be a reason to snub patrons with obvious virtual information needs. Third, several authors acknowledged the potential for SNS to be used as virtual comment boxes to monitor what people are saying about the library and how they experience it, or about potential services that library patrons think would benefit them. ${ }^{82}$ Yik Yak, because of its near total anonymity, was an ideal platform for gathering candid commentary. In addition to the feedback on library services, the responses posted on this platform could help us indirectly analyze the success of our instructional programs based on the number of correct peer-to-peer responses. The clarity and findability of hours, signs, and policies on websites and within buildings also could be judged using this feedback. In conclusion, significant opportunities exist on SNS to expand and improve library services to virtual information seekers.

\section{Acknowledgements}

The author would like to thank Rebecca Richardson and A.J. Boston for their assistance with data collection and analysis.

\section{Notes}

1 Andrew Perrin, Social Media Usage: 2005-2015 (Washington, D.C.: Pew Research Center, 2015).

2. Dianna E. Sachs, Edward J. Eckel, and Kathleen A. Langan, "Striking a Balance: Effective Use of Facebook in an Academic Library," (2011). University Libraries Faculty \& Staff Publications. Paper 18, available online at http://scholarworks.wmich.edu/library_pubs/18; Scott Stone, "Breaking the Ice: Facebook Friending and Reference Interactions," Reference \& User Services Quarterly 54, no. 1 (2014): 44-49; Adeyinka Tella and Toyese Tunde Oyedokun, "An Evaluation of Online Reference Services through Social Networking Sites in Selected Nigerian University Libraries," Reference Librarian 55, no. 4 (2014): 343-67.

3. Jill Benn and Dawn McLoughlin, "Facing Our Future: Social Media Takeover, Coexistence or Resistance? The Integration of Social Media and Reference Services," World Library and Information Congress: IFLA General Conference and Assembly Proceedings (2013), available online at http:// library.ifla.org/129/1/152-benn-en.pdf [accessed 2 August 2016].

4. Jill L. Creighton, Jason W. Foster, Libby Klingsmith, and Darren K. Withey, "I Just Look It Up: Undergraduate Student Perception of Social Media Use in Their Academic Success," Journal of Social Media in Society 2, no. 2 (2013); Andrea Forte, Michael Dickard, Rachel Magee, and Denise E. Agosto, "What Do Teens Ask Their Online Social Networks? Social Search Practices among High School Students," CSCW '14 Proceedings of the 17th ACM Conference on Computer Supported Cooperative Work \& Social Computing (2014): 28-37; Kyung-Sun Kim, Sei-Ching Joanna Sin, and EunYoung Yoo-Lee, “Undergraduates' Use of Social Media as Information Sources," College $\mathcal{E}$ Research Libraries 75, no. 5 (2014): 442-57; Amanda Lenhart, Teens, Social Media \& Technology Overview 2015 (Washington, D.C.: Pew Research Center, 2015); Gerald C. Kane, “Why Social Engagement May Be More Important Than Marketing," MIT Sloan Management Review 57, no. 1 (2015).

5. Bettina Peacemaker, Sue Robinson, and Emily Hurst, "Connecting Best Practices in Public Relations to Social Media Strategies for Academic Libraries," College \& Undergraduate Libraries 23, no. 1 (2016): 101-08.

6. Donald K. Wright and Michelle Drifka Hinson, “Examining Social and Emerging Media Use in Public Relations Practice: A Ten-Year Longitudinal Analysis," Public Relations Journal 9, no. 2 (2015): 1-26. 
7. Peacemaker, Robinson, and Hurst, "Connecting Best Practices in Public Relations," 105.

8. TBI Communications, Use of Social Media by the Library: Current Practices and Future Opportunities (London: Taylor \& Francis Group, 2014).

9. Randy Reichardt, "How May I Help Thee? Let Me Count the 2.0 Ways..." Internet Reference Services Quarterly 13, no. 2/3 (2008): 271-80.

10. Terra B. Jacobson, "Facebook as a Library Tool: Perceived vs. Actual Use," College \& Research Libraries 72, no. 1 (2011): 79-90; Samuel Kai-Wah Chu and Helen S. Du, "Social Networking Tools for Academic Libraries," Journal of Librarianship and Information Science 45, no. 1 (2012): 64-75.

11. Beth Evans, "Your Space or MySpace?" netconnect (Fall 2006): 8-12.

12. Eric Stoller, "Don't Ban Yik Yak," Inside Higher Ed (blog January 22, 2015), available online at https://www.insidehighered.com/blogs/student-affairs-and-technology/dont-ban-yik-yak [accessed 1 December 2016].

13. "Guidelines," Yik Yak (2016), available online at https://safety.yikyak.com/community [accessed 1 December 2016].

14. "FAQs," Yik Yak (2016), available online at www.yikyak.com [accessed 1 December 2016].

15. Tasnim Shamma, "Yik Yak Tests Universities' Defense of Free Speech," NPR (January 23, 2016), available online at www.npr.org/sections/alltechconsidered/2016/01/23/463197593/yik-yaktests-universities-defense-of-free-speech [accessed 1 December 2016]

16. Kate Russell, "Protest Sparks Social Media Reaction," Murray State News (Sept. 5, 2014), available online at http://thenews.org/2014/09/05/protest-sparks-social-media-reaction/ [accessed 1 December 2016]; Caitlin Dewey, "What Is Yik Yak, The App That Fielded Racist Threats at University of Missouri?" Washington Post (Nov. 11, 2015), available online at https://www.washingtonpost.com/news/the-intersect/wp/2015/11/11/what-is-yik-yak-the-app-that-fielded-racistthreats-at-university-of-missouri/ [accessed 1 December 2016]; Jonathan Mahler, "Who Spewed That Abuse? Anonymous Yik Yak App Isn't Telling," New York Times (Mar. 8, 2015), available at www.nytimes.com/2015/03/09/technology/popular-yik-yak-app-confers-anonymity-and-deliversabuse.html [accessed 1 December 2016]; Sara Jean Green, "WWU Student Charged with Hate Crime for Alleged Online Threats," Seattle Times (Dec. 10, 2015), available online at www.seattletimes.com/seattle-news/crime/wwu-student-charged-with-hate-crime-for-alleged-online-threats/ [accesssed 1 December 2016]; Peter Schmidt, “Women's Groups Urge Colleges and Government to Rein In Yik Yak," Chronicle of Higher Education (October 21, 2015), available online at http:// chronicle.com/article/Women-s-Groups-Urge-Colleges/233864 [accessed 1 December 2016].

17. Martin Saveski, Sophie Chou, and Deb Roy, "Tracking the Yak: An Empirical Study of Yik Yak," Proceedings of the Tenth International AAAI Conference on Web and Social Media (2016): 671-74.

18. Erik W. Black, Kelsey Mezzina, and Lindsay A. Thompson, "Anonymous Social Media: Understanding the Content and Context of Yik Yak," Computers in Human Behavior 57 (2016): $17-22$.

19. Reference and User Services Association, Measuring and Assessing Reference Services and Resources: A Guide (2012), available online at http://connect.ala.org/node/97245 [accessed 30 November 2016].

20. MARS Digital Reference Guidelines Ad Hoc Committee, Guidelines for Implementing and Maintaining Virtual Reference Services (2004), available online at http://www.ala.org/rusa/sites/ala. org.rusa/files/content/GuidelinesVirtualReference_2017.pdf [accessed 1 December 2016].

21. Khalid Mahmood and John V. Richardson, "Impact of Web 2.0 Technologies on Academic Libraries: A Survey of ARL Libraries," Electronic Library 31, no. 4 (2013): 508-20.

22. Leila June Rod-Welch, "Incorporation and Visibility of Reference and Social Networking Tools on ARL Member Libraries' Websites," Reference Services Review 40, no. 1 (2012): 138-71.

23. Chu and $\mathrm{Du}$, "Social Networking Tools for Academic Libraries."

24. TBI Communications, Use of Social Media by the Library, 4.

25. Forte, Dickard, Magee, and Agosto, "What Do Teens Ask Their Online Social Networks?"

26. Kim, Sin, and Yoo-Lee, “Undergraduates' Use of Social Media as Information Sources," 447.

27. Lenhart, Teens, Social Media \& Technology Overview 2015, 2.

28. Ibid., 22.

29. Moriah Balingit, "Millions of Teens Are Using a New App to Post Anonymous Thoughts, and Most Parents Have No Idea," Washington Post (Dec. 8, 2015), available online at http://wapo. st/1NhchWP?tid=ss_tw [accessed 1 December 2016]

30. Benn and McLoughlin, "Facing Our Future," 6.

31. Lizah Ismail, "What Net Generation Students Really Want," Reference Services Review 38, no. 1 (2010): 10-27.

32. Tella and Oyedokun, "An Evaluation of Online Reference Services," 360.

33. Marian S. Ramos and Christine M. Abridgo, "Reference 2.0 in Action: An Evaluation of the Digital Reference Services in Selected Philippine Academic Libraries," Library Hi Tech News 29, no. 1 (2012): 8-20. 
34. Jacobson, "Facebook as a Library Tool," 84.

35. Sachs, Eckel, and Langan, "Striking a Balance," 14.

36. Daniel Mack, Anne Behler, Beth Roberts, and Emily Rimland, "Reaching Students with Facebook: Data and Best Practices," Electronic Journal of Academic and Special Librarianship 8, no. 2 (2007).

37. Stone, "Breaking the Ice," 47.

38. Evans, "Your Space or MySpace?" 9.

39. Kaya van Beynen and Camielle Swenson, "Exploring Peer-to-Peer Library Content and Engagement on a Student-Run Facebook Group," College \& Research Libraries 77, no. 1 (2016): $34-50$.

40. Raymond Pun, "WeChat in the Library: Promoting a New Virtual Reference Service Using a Mobile App," Library Hi Tech News 32, no. 6 (2015): 9-11.

41. Dora Yu-Ting Chen, Samuel Kai-Wah Chu, and Shu-Qin Xu, "How Do Libraries Use Social Networking Sites to Interact with Users?" Proceedings of the American Society for Information Science and Technology 49, no. 1 (2012): 1-10.

42. Gary Collins and Anabel Quan-Haase, "Are Social Media Ubiquitous in Academic Libraries? A Longitudinal Study of Adoption and Usage Patterns," Journal of Web Librarianship 8 (2014): 48-68.

43. Evgenia Vassilakaki and Emmanouel Garoufallou, “The Impact of Twitter on Libraries: A Critical Review of the Literature," Electronic Library 33, no. 4 (2015): 795-809.

44. Darcy Del Bosque, Sam A. Leif, and Susie Skarl, "Libraries Atwitter: Trends in Academic Library Tweeting," Reference Services Review 40, no. 2 (2012): 199-213.

45. Erin Fields, "A Unique Twitter Use for Reference Services," Library Hi Tech News 27, no. 6/7 (2010): 14-15.

46. Katy Kelly and Hector Escobar, "Bird's Eye View: Using Twitter in \#ClubRoesch," College E Research Libraries Newws 76, no. 8 (2015): 433-36.

47. Valerie Forrestal, "Making Twitter Work: A Guide for the Uninitiated, the Skeptical, and the Pragmatic," Reference Librarian 52 (2011): 146-52.

48. Steven Bell, "Students Tweet the Darndest Things about Your Library-And Why You Need to Listen," Reference Services Review 40, no. 2 (2012): 217-20.

49. Besiki Stvilia and Leila Gibradze, "What Do Academic Libraries Tweet About, and What Makes a Library Tweet Useful?" Library \& Information Science Research 36, no. 3 (2014): 136-41.

50. van Beynen and Swenson, "Exploring Peer-to-Peer Library Content and Engagement."

51. Chen, $\mathrm{Chu}$, and $\mathrm{Xu}$, "How Do Libraries Use Social Networking Sites?"; Stvilia and Gibradze, "What Do Academic Libraries Tweet About?"

52. Chen, $\mathrm{Chu}$, and $\mathrm{Xu}$, "How Do Libraries Use Social Networking Sites?"

53. Stvilia and Gibradze, "What Do Academic Libraries Tweet About?"

54. Bella Karr Gerlich and G. Lynn Berard, "Testing the Viability of the READ Scale (Reference Effort Assessment Data)(C: Qualitative Statistics for Academic Reference Services," College E Research Libraries 71, no. 2 (2010): 116-37.

55. National Center for Education Statistics, Digest of Education Statistics 2012 (Washington, D.C.: U.S. Department of Education, 2013), available online at http://nces.ed.gov/pubs2014/2014015. pdf [accessed 30 November 2016]; National Center for Education Statistics, Digest of Education Statistics 2014 (Washington, D.C.: U.S. Department of Education, 2016), available online at http:// nces.ed.gov/pubs2016/2016006.pdf [accessed 30 November 2016].

56. Lynn Silipigni Connaway, Timothy J. Dickey, and Marie L. Radford, "If It Is Too Inconvenient, I'm Not Going after It: Convenience as a Critical Factor in Information-Seeking Behaviors," Library and Information Science Research 33 (2011): 179-90.

57. Marie L. Radford, Lynn Silipigni Connaway, Jeffrey Pomerantz, Lorri Mon, and Joseph Janes, "E-Valuating E-Reference: Transforming Digital Reference Through Research and Evaluation," Proceedings of the American Society for Information Science and Technology (2008): 1-11.

58. Forte, Dickard, Magee, and Agosto, "What Do Teens Ask Their Online Social Networks?"

59. A noob, according to Urban Dictionary, is "a person who is new or inexperienced in a subject, usually an online game. Noobs are usually annoying and excessively stupid."

60. Creighton. Foster, Klingsmith, and Withey, "I Just Look It Up," 22.

61. Mary Jane Swope and Jeffrey Katzer, “The Silent Majority: Why Don't They Ask Questions?" RQ (1972): 161-66; Peter Hernon and Maureen Pastine, "Student Perceptions of Academic Librarians," College \& Research Libraries 38, no. 2 (1977): 129-39; Margie Ruppel and Jody Condit Fagan, "Instant Messaging Reference: Users' Evaluation of Library Chat," Reference Services Review 30, no. 3 (2002): 183-97.

62. van Beynen and Swenson, "Exploring Peer-to-Peer Library Content and Engagement," 46.

63. Jan H. Kietzmann, Kristopher Hermkens, Ian P. McCarthy, and Bruno S. Silvestre. "Social Media? Get Serious! Understanding the Functional Building Blocks of Social Media," Business 
Horizons 54 (2011): 241-51.

64. Thirsty, according to Urban Dictionary, means "Too eager to get something (especially [any type of sexual relations])."

65. Rich Gazan, "Social Q\&A," Journal of the American Society for Information Science and Technology 62, no. 12 (2011): 2301-12.

66. Julie Arnold and Neal K. Kaske, "Evaluating the Quality of a Chat Service," portal: Libraries and the Academy 5, no. 2 (2005): 177-93; Jeffrey Pomerantz, Lili Luo, and Charles R. McClure, "Peer Review of Chat Reference Transcripts: Approaches and Strategies," Library E Information Science Research 28, no. 1 (2006): 24-48; Sarah Maximiek, Erin Rushton, and Elizabeth Brown, "Coding into the Great Unknown: Analyzing Instant Messaging Session Transcripts to Identify User Behaviors and Measure Quality of Service," College E Research Libraries 71, no. 4 (2010): 361-74; Marie L. Radford and Lynn Silipigni Connaway, "Not Dead Yet! A Longitudinal Study of Query Type and Ready Reference Accuracy in Live Chat and IM Reference," Library E Information Science Research 35, no. 1 (2013): 2-13; Kate Fuller and Nancy H. Dryden, "Chat Reference Analysis to Determine Accuracy and Staffing Needs at One Academic Library," Internet Reference Services Quarterly 20, no. 3/4 (2015): 163-81.

67. Yin Zhang and Shengli Deng, "Social Question and Answer Services Versus Library Virtual Reference: Evaluation and Comparison from the Users' Perspective," Information Research 19, no. 4 (2014).

68. Rich Gazan, "Seekers, Sloths, and Social Reference: Homework Questions Submitted to a Question-Answering Community," New Review of Hypermedia and Multimedia, 13 no. 2 (2007): 239-248; Vanessa Kitzie and Chirag Shah, "Faster, Better, or Both? Looking at Both Sides of Online Question-Answering Coin," Proceedings of the American Society for Information Science and Technology 48, no. 1 (2011): 1-4; Zhang and Deng, "Social Question and Answer Services Versus Library Virtual Reference."

69. Benn and McLoughlin, "Facing Our Future," 8.

70. Reference and User Services Association, Measuring and Assessing Reference Services and Resources.

71. Brian Mathews, "Moving beyond the Reference Desk: Being Where Users Need Us," Reference Librarian 48, no. 2 (2007): 9-13.

72. Mori Lou Higa, "Integration of Web 2.0 and Electronic Journals," Journal of Electronic Resources in Medical Libraries 5, no. 1 (2008): 55-64.

73. Peacemaker, Robinson, and Hurst, "Connecting Best Practices in Public Relations," 107.

74. Ibid., 110 .

75. Allison Faix, "Peer Reference Revisited: Evolution of a Peer-Reference Model," Reference Services Review 42, no. 2 (2014): 305-19; Brett B. Bodemer, "They CAN and They SHOULD: Undergraduates Providing Peer Reference and Instruction," College E Research Libraries 75, no. 2 (2014): 162-78; Mary O’Kelly, Julie Garrison, Brian Merry, and Jennifer Torreano, "Building a PeerLearning Service for Students in an Academic Library," portal: Libraries and the Academy 15, no. 1 (2015): 163-82; Michael M. Smith and Leslie J. Reynolds, "The Street Team: An Unconventional Peer Program for Undergraduates," Library Management 29, no. 3 (2008): 145-58.

76. Kietzmann, Hermkens, McCarthy, and Silvestre, “Social Media? Get Serious!” 244.

77. Lyndelle Gunton and Kate Davis, "Beyond Broadcasting: Customer Service, Community and Information Experience in the Twittersphere," Reference Services Review 40, no. 2 (2012): 224-.27.

78. Ibid., 225.

79. Forte, Dickard, Magee, and Agosto, "What Do Teens Ask Their Online Social Networks?"

80. Dara Fontein, "The Top Social Media Sites That Matter to Marketers," Hootsuite (Mar. 23, 2016), available online at https://blog.hootsuite.com/top-social-media-sites-matter-to-marketers/ [accessed 1 December 2016].

81. Peacemaker, Robinson, and Hurst, "Connecting Best Practices in Public Relations," 107.

82. Forrestal, "Making Twitter Work," 148; Bell, "Students Tweet the Darndest Things," 220; Evans, "Your Space or MySpace?" 9. 